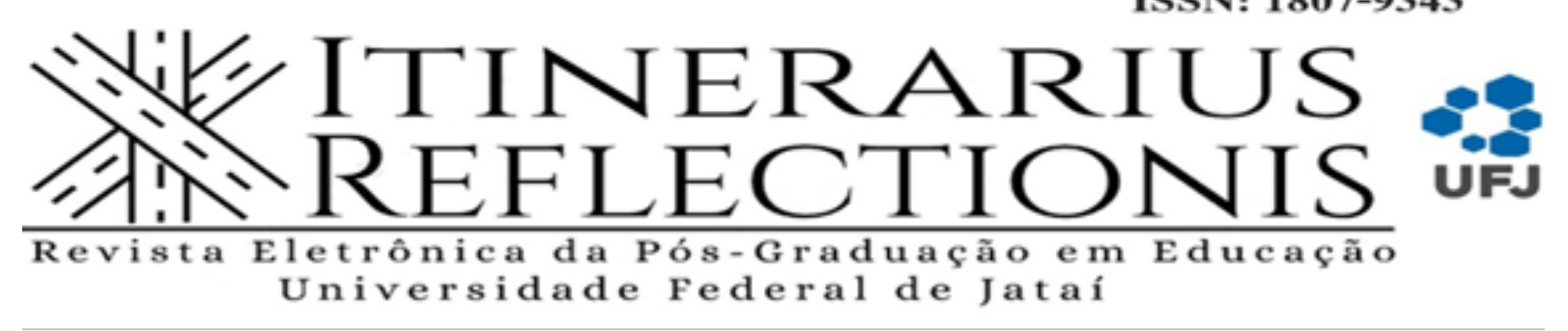

Volume 17, n. 2, ano 2021

\title{
Ensino da arquitetura funcional da memória, ilusões, mitos e técnicas para um aprendizado efetivo: tornando-se um aprendiz sofisticado
}

Resumo: Apesar de passar-se grande parte da vida estudando, pouquíssima ou quase nenhuma parte dos anos de estudo é dedicada ao ensino do como estudar de forma eficaz. Espera-se, por meio do ensino e avaliação dos vários outros conceitos e competências, que a prática constante de estudo, por si própria, seja capaz de habilitar o indivíduo a aprender de forma eficaz. Seria 'saber aprender' uma competência inata dos indivíduos? E a prática do estudo um processo capaz de desenvolvê-la em seu completo potencial? Teriam os ingressantes da graduação maturado esta competência a ponto de não ser necessário avaliar o seu domínio? A avaliação do aprendizado das demais competências - línguas, matemática, ciência e suas tecnologias - seria suficiente para atestar a habilidade de aprender do estudante? Afinal, a graduação e, posteriormente, a pós-graduação, constituirão os anos de estudo mais intensos da vida e quando mais se necessitará de um domínio completo de técnicas eficazes de aprendizagem. Na direção das respostas para estas perguntas, apresenta-se aqui uma pesquisa de finalidade básica, com estudo exploratório, de natureza quasi-qualitativa e delineamento de pesquisa documental, com resultados científicos sobre as peculiaridades do aprendizado e memória humanos. Destaca-se o quão iludidos estão os estudantes, em geral, em relação a sua habilidade de aprender e à eficácia das técnicas que usam durante o estudo. Esclarecendo alguns mitos e ilusões à luz de resultados científicos e apresentando técnicas mais efetivas - como o conceito de dificuldades desejadas, intercalação, testes distribuídos, aptidão e desenvolvimento da criatividade - tem-se o objetivo de conscientizar os estudantes dos resultados da ciência a este respeito e fomentar a potencialização do aprendizado de longo prazo.

Palavras-chave: Autoaprendizagem. Ilusões e Mitos de Aprendizado. Técnicas de Aprendizado Eficazes.

\section{Teaching functional memory architecture, illusions, beliefs, and techniques for effective learning: becoming a sophisticated learner}

\begin{abstract}
Although we dedicate a large part of our lives to formal education, we have little or even no opportunity during all those years to learn how to study effectively. We hope, by teaching and evaluating other concepts and competencies, that the study practice, on its own, can enable us to learn effectively. Is 'knowing how to learn' an innate competence of individuals? Is study practice a process capable of fully developing it? Did the undergraduate students mature this competence to the point that it is unnecessary to evaluate their mastery? Would the assessment of other competencies - language, mathematics, science,

\footnotetext{
${ }^{1}$ Doutor em Ciência da Computação, com ênfase em Sistemas Distribuídos, pela Universidade Federal de Goiás (UFG), Professor Adjunto da Universidade Federal de Jatai (UFJ). E-mail: thborges@ufj.edu.br
} 
and technologies - be sufficient to attest the learn ability of students? After all, the students have their most intense years of study in academia, and a mastery of effective learning techniques will benefit them the most. To answers these questions, we survey recent research on the peculiarities of human learning and memory. We highlight how misguided the students are, in general, about their ability to learn and the effectiveness of the techniques they use to study. Clarifying some beliefs and illusions in the light of scientific results, presenting more effective techniques - such as the concept of desired difficulties, interleaving, distributed testing, creativity ability, and creativity growth - we aim to make students aware of science results and foster the enhancement of long-term learning.

Keywords: Self-learning. Learning Illusions and Beliefs. Effective Learning Techniques.

\section{INTRODUÇÃO}

Na noite anterior à prova do dia seguinte, está a estudante agarrada aos livros e em seu computador, este apinhado de arquivos, slides, alguns exercícios resolvidos, as soluções que o professor disponibilizou. A correria e as eventualidades do dia a dia a fizeram postergar o estudo até ser inadiável, improrrogável - a tão comentada procrastinação. Durante quase toda a noite ela relê, sublinha, destaca. Aprendeu estas técnicas com seus colegas ou até mesmo professores, e tem dado resultado, afinal, ingressou na graduação. Certamente, o que ela revisa ou estuda durante a noite a ajudará no exame do dia seguinte. No entanto, exceto pelo estudo de última hora que já é um tabu, seriam as demais práticas eficazes para promover compreensão, retenção e transferência para novos problemas ou desafios humanos? Teria a estudante aprendido a aprender em sua educação formal?

Apesar de passarmos grande parte da vida estudando, poucos de nós somos instruídos a como estudar ${ }^{2}$ de forma eficaz (BJORK; DUNLOSKY; KORNELL, 2013). Preocupa-se a muito tempo com o currículo, o conteúdo, o saber ensinar e o saber avaliar, como pode-se ver, por exemplo, no Brasil de meio século atrás (BRASIL, 1971) e numa discussão mais recente do problema nos últimos 50 anos de Coêlho (2012). Recentemente, houve avanço na definição de competências e habilidades e cada vez mais estabelece-se a importância do saber aprender no mundo globalizado (MEC; CONSED; UNDIME, 2017). No entanto, falta concretizar o como desenvolver esta habilidade ou competência. ${ }^{3}$ Poderíamos pensar, por um momento, que sabendo o professor ensinar e avaliar, estaria o estudante apto a perceber e desenvolver o saber aprender. No entanto, sabemos que na maioria das metodologias de ensino desenvolvidas nas últimas décadas, o estudante é partícipe quando não protagonista do processo de ensino aprendizagem (JOHNSON; JOHNSON, 2008; BACICH; MORAN, 2018).

\footnotetext{
${ }^{2}$ Em toda a minha educação formal, nunca cursei uma disciplina, seminário ou similar ensinando técnicas de estudo ou o que é aprender de fato. O contato com as técnicas aqui discutidas, já no doutorado, conscientizou-me do porquê não lembrava de muito do que havia estudado quando precisava transferi-lo para novos problemas.

${ }^{3} \mathrm{~A}$ importância do saber aprender é destacada na apresentação do documento (MEC; CONSED; UNDIME, 2017) mas observe que 'aprender a aprender' é mencionado, ligeiramente, na competência específica 7, juntamente com práticas de linguagem no universo digital, e não faz parte diretamente de nenhuma habilidade da competência além de não estar, em nenhum dos casos, vinculada ao como estudar.
} 
Pode-se hipotetizar também que, por si próprios, o ensino e a avaliação dos vários conceitos, competências, habilidades, o próprio processo ou a prática constante de estudo sejam capazes de habilitar o indivíduo a aprender de forma eficaz. Saber aprender seria, nesse caso, uma competência inata dos indivíduos e a prática do estudo um processo capaz de desenvolvêla em seu completo potencial. A pergunta ressurge: teriam os ingressantes da graduação, por já terem praticado por tanto tempo e de tantas formas, maturado esta competência a ponto de não ser mais necessário avaliar o seu domínio? Ou será que a avaliação das demais competências do indivíduo - língua portuguesa, matemática, ciência e suas tecnologias - seria suficiente para atestar sua habilidade de aprender? Precisa-se desta resposta. Afinal, não se avalia esta habilidade nos exames de ingresso das universidades, e, ainda, a graduação e pós-graduação constituirão os anos de estudo mais intensos da vida; o momento em que mais se necessitará do domínio de técnicas eficazes de aprendizagem.

Adicionalmente, são muitas e crescentes as oportunidades de aprendizado fora das salas de aula formais, principalmente as mediadas por tecnologias da informação, nas quais o estudante é, inevitavelmente, o principal protagonista de seu aprendizado. Nelas incluemse o Ensino a Distância $(\mathrm{EaD})$, também as diversas estratégias e metodologias de ensino implementadas durante a pandemia mundial de Covid-19, e os vários cursos a distância ofertados por instituições de ensino, no Brasil e no exterior, na forma de cursos massivos online. Saber como regular e administrar seu próprio aprendizado tem se tornado cada vez mais importante (DUNLOSKY, 2013; BJORK; DUNLOSKY; KORNELL, 2013), mas de forma alguma estão os estudantes habilitados, como pode-se perceber numa amostra de suas percepções, em relatos próprios, organizados no livro Vozes durante a pandemia em 2020 (OLIVEIRA; OLIVEIRA, 2020).

Por sorte, o avanço da ciência no entendimento dos fundamentos da memória humana (neurociência), as pesquisas sobre processos cognitivos do aprendizado (psicologia), e a incessante busca por metodologias de ensino aprendizagem (educação e ensino), têm apontado caminhos concretos sobre técnicas eficazes de aprendizagem, tanto para os estudantes quanto para professores. É neste avanço que debruça-se no restante deste texto, com o objetivo de integrar e popularizar as descobertas científicas relacionadas a se tornar um aprendiz sofisticado, ou seja, um aprendiz que sabe estudar de modo a aprender, capaz de reter a compreensão para posteriormente transferi-la para novos problemas.

Esta é, portanto, uma pesquisa de finalidade básica, com estudo exploratório, de natureza quasi-qualitativa e delineamento de pesquisa documental. Em palavras simples, um levantamento para popularização da ciência, com uma pequena pretensão de ser texto formativo e conscientizador. Limitou-se em explorar a interseção entre as áreas mencionadas e em apresentar princípios e técnicas gerais, no sentido que podem ser incorporadas em várias metodologia de ensino ou aplicadas com uma simples reorganização da forma de estudar, sem necessitar de novas ferramentas, tecnologias da informação, ou mesmo de um computador. 
Apresenta-se, a princípio, avanços no entendimento da memória humana e em como se dá o aprendizado (Seção 2). Por meio de uma comparação com as memórias artificiais, aspectos fundamentalmente distintos do cérebro são apresentados, com o objetivo de subsidiar a análise da eficácia ou limitação das técnicas de estudo posteriormente. Segue-se com o papel do sono no aprendizado e a sua importância na retenção, memória de longo prazo (Seção 3).

Discute-se evidências de que as práticas de estudo mencionadas no primeiro parágrafo desta introdução são as principais e, às vezes, as únicas usadas pelos estudantes (Seção 4). Discorre-se, na sequência, sobre técnicas gerais de aprendizado eficaz, como testar ao invés de reler, espaçar o estudo ao invés de estudar massivamente, intercalar a solução dos exercícios ao invés de resolvê-los de forma agrupada, interrogação elaborativa, dentre outras (Seção 5). Discute-se, também, as possibilidades e impossibilidades relacionadas a criatividade (Seção 6). Por fim, apresenta-se considerações finais (Seção 7).

\section{ARQUITETURA FUNCIONAL DA MEMÓRIA HUMANA}

O cérebro humano é uma estrutura bem complexa. Estima-se que ele possua cerca de 86.1 bilhões de neurônios (+/- 8.1 bilhões) e um número similar de outras células chamadas nãoneuronais, que proveem suporte e proteção aos neurônios (AZEVEDO et al., 2009). A Figura 1 ilustra algumas partes de um neurônio, importantes para o entendimento deste texto. Cada neurônio é uma célula especial que contém dendritos, ou receptores, que são as ramificações ligadas ao núcleo da célula; contém também um axônio, que é o transmissor, a "cauda" na figura. Por simplicidade, adota-se os termos receptores e transmissores no restante do texto. $\mathrm{Na}$ extremidade do transmissor também existem algumas ramificações e em cada uma delas existem sinapses. Cada sinapse entra em contato com um receptor de outro neurônio.

Figura 1: Ilustração de um neurônio com as estruturas mencionadas no texto nomeadas.

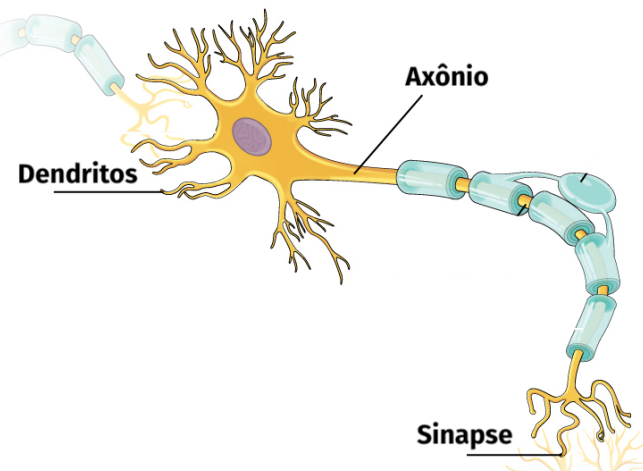

Fonte: Imagem adaptada de (OPENSTAX, 2021), CC BY 4.0.

Atualmente, pode-se observar como estas estruturas realmente são. A Figura 2a apresenta uma renderização $3 \mathrm{D}$ de receptores e transmissores reais. Esta imagem foi obtida usando microscopia eletrônica de seção serial, em inglês serial section electron microscopy, apoiada por computação gráfica que, juntamente, possibilitam a reconstrução $3 \mathrm{D}$ de parte 
do cérebro. Os receptores aparecem em amarelo na figura. O transmissor aparece em preto, semitransparente, e, naturalmente, é de um segundo neurônio. As partes em vermelho são as sinapses. Note que as setas em rosa indicam onde o transmissor se conecta com o receptor, através de sinapses. Em algumas regiões do cérebro, existem milhares destas sinapses em cada neurônio, e sabe-se que este número de conexões varia muito de região para região (LITWINKUMAR et al., 2017). Uma sinapse aparece, em detalhes, na Figura 2b. Estes pequenos pontos acinzentados são vesículas, por onde sinais químicos ou elétricos se propagam. Esta é uma sinapse de aproximadamente 300nm de largura, cerca de três vezes a escala. Na Figura 2c há duas sinapses, coloridas, da perspectiva do transmissor, semitransparente. O transmissor não encosta, há um espaço entre ele e a sinapse, que é mais perceptível na Figura 2a, na segunda seta da esquerda para direita.

Figura 2: Reconstrução 3D de: (a) receptores (dendritos) em amarelo e transmissores (axônios) de um segundo neurônio em preto, semitransparente, com setas em rosa indicando sinapses, (b) uma sinapse, e (c) um transmissor (axônio) com duas sinapses. Imagens geradas por microscopia eletrônica de seção serial seguidas de modelagem 3D.

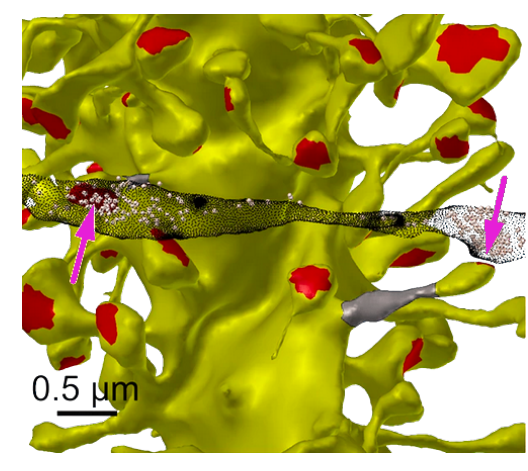

(a)

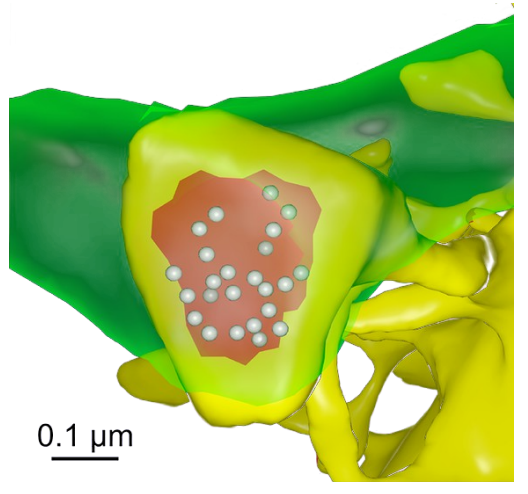

(b)

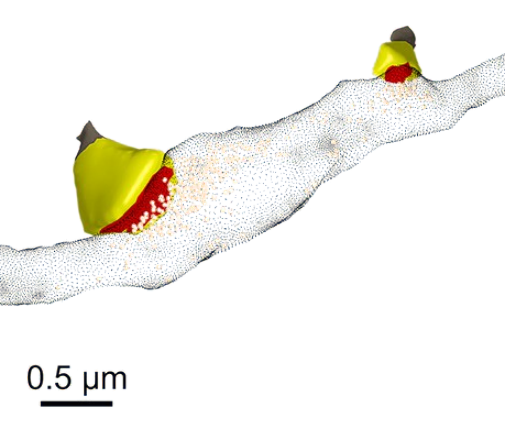

(c)

Fonte: Imagens adaptadas de (BARTOL THOMAS M et al., 2015), DOI: (2a) 10.7554/eLife . 10778.011a, (2b) 10.7554/eLife.10778.005 e (2c) 10.7554/eLife.10778.014. CC BY 4.0 .

É importante observar estas imagens para entender como a informação é registrada ou como o aprendizado de fato acontece no cérebro, biologicamente. Tem a ver com o tamanho e a quantidade dessas conexões. Elas formam redes complexas e dinâmicas, que mudam conforme novas memórias são armazenadas (BARTOL THOMAS M et al., 2015). Portanto, a informação é de certa forma memorizada, ou gravada, com modificações na estrutura do cérebro, através de um processo biológico que altera o tamanho das sinapses, que cria ou refaz as conexões dos transmissores, e até no comprimento dos receptores. O sono, inclusive, tem uma participação importante nesta dinâmica (YANG et al., 2014), como detalhado na próxima seção.

A memória divide-se em dois tipos principais: de curto e de longo prazo. A memória de trabalho, do tipo curto prazo, é pequena e cabe de cinco a nove itens simultaneamente, apenas, e se perde com facilidade; dura em torno de 30 segundos. A memória de longo prazo, ao contrário, é onde registramos eventos, episódios, conhecimentos gerais. Ela também é 
subdividida, há uma parte consciente e outra inconsciente. Nesta última, ficam os procedimentos como falar, andar, dentre outros (SAH, 2017).

Um pequeno teste pode ajudar a entender as limitações e capacidades da memória de trabalho. Olhe para as doze letras a seguir por cinco segundos: RGK KPL TDY FGQ. Depois de contar até cinco, cubra-as com um pedaço de papel, ou com seus dedos, e leia a nota de rodapé. ${ }^{4}$

Este teste apresentou uma limitação importante em relação a quantidade de itens que conseguimos armazenar na memória para trabalhar e formar conceitos mais complexos. Outro teste, porém com mais letras. Olhe para elas também por cinco segundos: UFJ BOLA FITA BRAIN. Da mesma forma, depois de contar até cinco, cubra-as e leia a nota de rodapé. ${ }^{5}$

Ao agrupar as letras em palavras, elas tornam-se um bloco, com uma semântica associada e já registrada no cérebro, ou seja, é um só item. Quatro itens cabem na memória de curto prazo! Recuperar as letras faltantes, neste caso, consiste em buscar na memória de longo prazo a composição da palavra, que já havia sido registrada no passado. Se você teve dificuldade com a palavra BRAIN, que significa cérebro em inglês, talvez seja porque ainda não a associou ao respectivo conceito. Este é um fundamento importante da memória humana; uma capacidade incrível da qual deve-se ter consciência e usar em prol do aprendizado, ou seja, encontrar formas de agrupar itens desconexos, criar blocos, para que eles ocupem apenas uma posição na memória de trabalho.

A memória de longo prazo também tem características fundamentais das quais devese ter consciência. Um comparativo com as memórias artificiais, ou digitais, feitas pelo homem, é oportuno. O contato com tecnologia e o entendimento profundo do assunto é desnecessário; será apenas um exercício de comparação. Usa-se tanto essas memórias no dia a dia que tende-se a acreditar que o cérebro pode fazer os mesmos registros ou se comportar de forma equivalente.

A tecnologia de memória digital mais empregada atualmente é a memória flash, presente nos pendrives, cartões SD usados em câmeras, ou ainda nos discos SSD (Solid State Disks ou discos de estado sólido), que na verdade não são mais "discos", e sim dispositivos eletrônicos, como os pendrives, mas com maior velocidade e capacidade de armazenamento. A Figura 3 apresenta uma imagem microscópica de um pequeno pedaço de memória flash. É uma matriz de $32 \times 32$, cujas laterais possuem pontos de conexão, 16 em cada lado, por onde a eletricidade flui - o equivalente dos sinais químicos do cérebro. Cada quadrinho no centro é uma mini bateria que pode ser carregada ou descarregada, zero ou um (um bit), que é como os dados são memorizados. São necessários mais de 1 milhão de vezes esta estrutura para se ter um Gigabyte de capacidade, o que não dá pra armazenar nem um filme em qualidade Full HD. Mas

\footnotetext{
${ }^{4}$ Sem olhar as letras novamente, quais são as letras que faltam? R_K K K_ _DY FG_. Acertou? Se sim, parabéns! Antigamente, era costumeiro decorarmos os números de telefone das pessoas mais próximas. Hoje em dia, com a agenda em nossas mãos, nos smartphones, são poucos os que conseguem guardar um número de telefone ao ouvilo pela primeira vez. Quando a pessoa começa a falar já precisamos estar prontos para anotar. Sem um pouco de treino, inclusive, esquecemos até o nome de pessoas que acabamos de conhecer.

${ }^{5}$ Identifique as letras que faltam U_J B_L_ _ I_A B B $_{--} N$. Agora foi mais fácil?
} 
esta estrutura é muito pequena, assim como as sinapses no cérebro. A tecnologia atual consegue fabricá-la em nanoescala, replicando-a milhares de vezes em um milímetro quadrado.

Figura 3: Imagem microscópica de 1 KB (1024 bits) de memória flash, projetada e construída na Rice University usando óxido de silício como componente ativo.

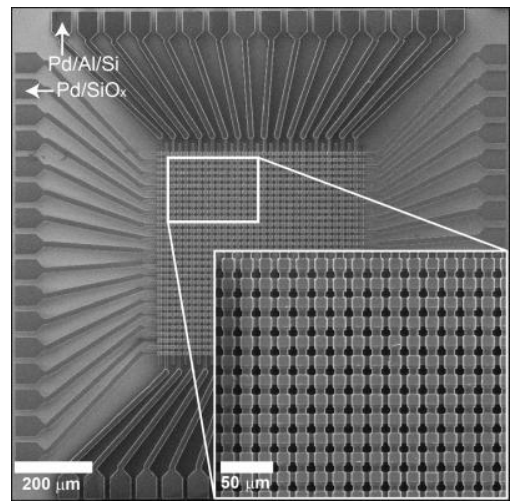

Fonte: Tour Group/Rice University (TOUR GROUP/RICE UNIVERSITY, 2021).

Portanto, a estrutura da memória digital é definida na fabricação. A estrutura do cérebro, ao contrário, é orgânica, flexível, e muda com o tempo. O armazenamento na memória digital dá-se em pequenos pontos que guardam carga elétrica e é literal, cumulativo. No cérebro, a estrutura é modificada para fazer o armazenamento: novas sinapses, receptores e transmissores são criados, novas conexões são formadas. Em contraste, a memória humana é associativa e não literal. Por exemplo, para reter uma informação é necessário associá-la com outros conceitos e semânticas já memorizados (SAH, 2017). Este é um dos fundamentos, portanto, do por que o estudante tem que ser ativo durante o aprendizado, refletindo sobre os novos conceitos para associá-los com outras informações já armazenadas. Bem diferente, portanto, da memória digital.

Outra característica importante é a retenção. A memória digital é persistente, com um tempo de duração entre 5 e 30 anos, dependendo do tipo. No cérebro, a retenção é volátil e depende do esforço do indivíduo em repetir a recuperação. Recuperar - relembrar - um conceito estudado recentemente significa marcá-lo como importante; as sinapses são fortalecidas e crescem, cria-se um caminho mais forte para recuperar posteriormente. Relembrar, portanto, também causa uma mudança estrutural no cérebro (BARTOL THOMAS M et al., 2015). Perceba que não é reler, reestudar, aprender novamente. Trata-se de relembrar (YAN; CLARK; BJORK, 2017; SAH, 2017).

Por último, a capacidade. Enquanto na memória digital a capacidade é fixa - definida na fabricação, a associatividade no cérebro permite a expansão da capacidade a medida que aumenta-se a rede de conceitos armazenados, ou seja, quanto mais aprende-se conceitos e habilidades, mais conceitos e habilidades podem ser associados aos já existentes, ou em termos científicos, um maior nível de conectividade neuronal está associado a uma maior possibilidade de produzir representações de estímulos com mais dimensões e suportar a aprendizagem associativa (LITWIN-KUMAR et al., 2017). Isso pode dar a impressão de que a memória no 
cérebro é infinita, o que obviamente não deve ser o caso, mas pelo menos parece justificar, eventualmente, o fato de aprender se tornar mais fácil com o tempo, isto é, a medida que aumenta-se a rede de associações.

\section{O SONO E O APRENDIZADO}

O sono está longe de ser um estado de inconsciência ou um tempo que não aproveitamos. Durante o sono, os mesmos neurônios ativados enquanto acordado são reativados; há uma repetição do que foi vivenciado, uma reativação das mesmas redes neurais (CURCIO; FERRARA; DE GENNARO, 2006). Essa reativação é um processo fundamental de consolidação relacionado ao aprendizado, no qual as experiências, por exemplo os conceitos e habilidades estudados, são mescladas em nossa memória de longo prazo (PEIGNEUX et al., 2001; KLINZING; NIETHARD; BORN, 2019), em uma interação cuidadosamente coreografada entre o hipocampo e o neocórtex, duas regiões do cérebro, durante o sono de ondas curtas, ou sono profundo (SAH, 2017).

Infelizmente, assim como o exemplo ilustrativo da estudante no início da introdução, que estava pronta para passar a noite estudando para a prova do dia seguinte, as pesquisas revelam que estudantes de todos os níveis de ensino são cronicamente privados do sono ou possuem um sono de qualidade ruim, seja por pressões psicossociais, do ambiente ou profissionais (veja a revisão em (CURCIO; FERRARA; DE GENNARO, 2006), e um levantamento mais recente em (JAMIESON et al., 2020)). A privação do sono, além de reduzir a atividade no hipocampo, aumenta a sonolência, provoca mudanças de comportamento e reduz a habilidade de memorizar e a capacidade de resolver problemas. Está diretamente relacionada com o desempenho acadêmico para melhor, quando o sono é adequadamente regulado, e para pior, quando ocorre a privação do sono (CURCIO; FERRARA; DE GENNARO, 2006). E o que é pior, a privação de sono está associada ao aparecimento de doenças agudas e crônicas, além de aumentar a mortalidade e morbidade por doenças cardiovasculares (LIU; CHEN, 2019).

Outra descoberta importante da ciência em relação ao aprendizado é que, durante o sono, ocorre a formação de espinhas dendríticas, ou linhas de receptores, associadas à retenção e aprendizado. A privação do sono reduz significativamente esta formação, conforme sugere o estudo de Yang et al. (2014). Os autores avaliaram a formação de receptores no cérebro em animais submetidos a um treinamento motor. Um grupo de ratos foi treinado a se equilibrar em um rotarod (um tipo de equipamento que gira enquanto os animais tentam se equilibrar) e posteriormente privado ou não do sono, seguido de medições que indicaram os níveis de formação de receptores. A Figura 4a apresenta o resultado do experimento. Oito horas após o treinamento, o grupo A, que treinou e depois dormiu, formou quase o dobro de receptores comparado ao grupo $\mathrm{B}$, que apesar de ter treinado da mesma forma, não dormiu. $\mathrm{O}$ grupo $\mathrm{C}$, que treinou duas vezes mas também não dormiu, apresentou um pequeno aumento, mas ainda menor que a formação do grupo A. O grupo D foi um grupo de controle, que não treinou nem dormiu. 
Observe que reforçar o aprendizado, sem dormir entre o estudo/reestudo, grupo C, melhora mas não compensa totalmente o efeito da perda de sono. Este era um caso análogo ao da estudante exemplo da introdução.

O estudo também acompanhou o desempenho dos animais na tarefa. Observa-se, na Figura $4 b$, que no primeiro dia, o grupo A teve uma melhora na performance de mais de $40 \%$, contra $20 \%$ do grupo B. Cinco dias depois, a diferença é ainda maior, $65 \%$ contra $25 \%$. Observa-se que compensar o sono, mais de um dia depois do aprendizado, não reverte a falta de formação dos receptores. Isso sugere que após perder o sono não é possível recuperar seus benefícios, ou seja, é como se o aprendizado, ou parte do mesmo, se perdesse.

Figura 4: Resumo do experimento de treinamento motor e a formação de espinhas dendríticas ou linhas de receptores. Em (a) a formação após $8 \mathrm{~h}$ do treinamento e em (b) a melhoria no desempenho após 1 e 5 dias.

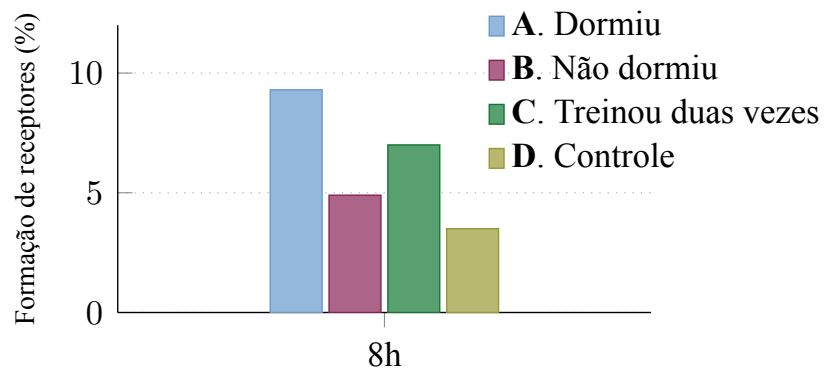

(a)

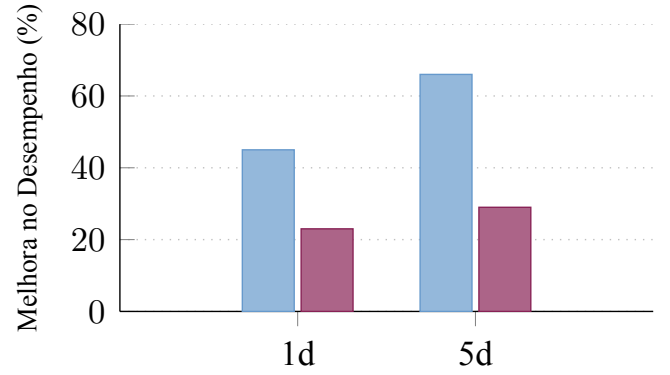

(b)

Fonte: O autor. Dados originais de (YANG et al., 2014).

\section{COMO OS ESTUDANTES ACREDITAM APRENDER?}

Quais técnicas os estudantes usam para estudar e que acreditam surtir efeito, gerar aprendizado? Teriam essas técnicas sido ensinadas a eles?

Um estudo da Universidade da Califórnia em Los Angeles (UCLA), envolvendo 472 estudantes, tentou capturar esta percepção dos calouros ao chegarem na universidade. $80 \%$ deles, ao serem perguntados se haviam sido ensinados a estudar da forma que o fazem, responderam que não (KORNELL; BJORK, 2007). Perguntados sobre como decidem o que estudar, 59\% responderam que estudam o mais urgente, o que precisarão entregar logo na sequência ou o que já passou da hora de estudar, enquanto apenas $11 \%$ disseram planejar seus estudos antecipadamente e seguir o cronograma. Ainda, $60 \%$ disseram reler as seções do caderno ou livro, as quais grifaram ou destacaram com marcador anteriormente, ou seja, adotam a técnica de destacar e reler para aprender.

A realidade talvez não seja tão distinta no Brasil, mesmo muitos anos depois da pesquisa acima. Em uma pesquisa em sala de aula, envolvendo 136 alunos da Universidade Federal de Jataí, em sua maioria calouros, perguntou-se questões similares para entender se havia ou não um planejamento de estudo por parte dos estudantes e quais seriam as técnicas 
mais frequentemente usadas para estudar. Quase 55\% dos participantes responderam estudar o que é mais urgente, ou seja, estudar de última hora, e apenas $18 \%$ afirmaram planejar e seguir um cronograma de estudos (Figura 5a). Quanto as técnicas de estudo (Figura 5b), 78\% relê o material para estudar e aproximadamente $67 \%$ destaca o texto. Preocupantes $41 \%$ estudam na noite antes da prova e apenas $24 \%$ afirmam participar ativamente das aulas. Outras estratégias interessantes são bem menos empregadas, como criação ou elaboração de diagramas, gráficos e desenhos (19,9\%) e uso de jogos ou flashcards (7\%) - cartões com perguntas e respostas.

Figura 5: Priorização do estudo e técnicas usadas por estudantes da UFJ. Em (a) a forma escolhida para priorizar o que estudar primeiro, e, em (b) as técnicas empregadas. Quase $82 \%$ não planeja ou possui cronograma de estudo e as técnica de estudo mais empregadas são reler e destacar texto.

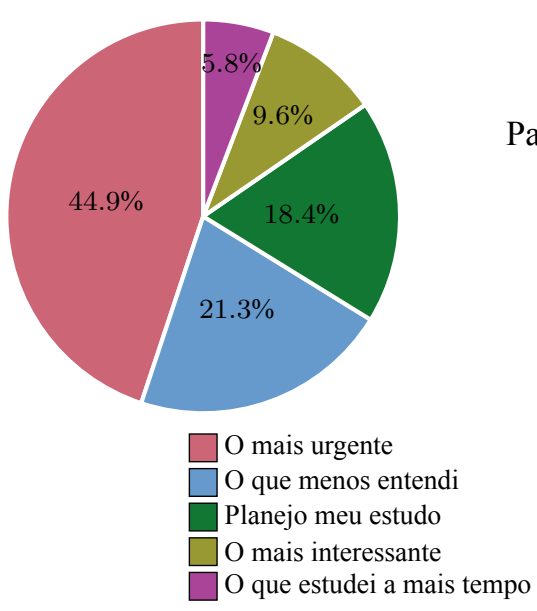

(a)

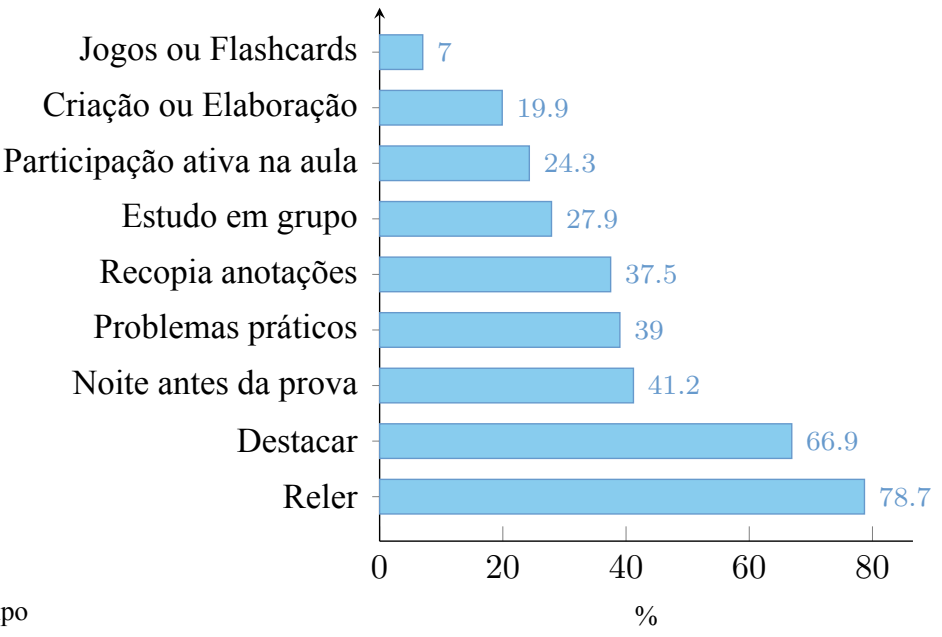

(b)

Fonte: $\mathrm{O}$ autor.

As evidências sugerem, portanto, que as práticas de estudo mencionadas no início do texto são de fato as principais e às vezes as únicas usadas pelos estudantes. Além de Kornell e Bjork (2007) e esta pesquisa local, este estudo também foi repetido com resultados consistentes por Hartwig e Dunlosky (2012). A meta análise de Miyatsu, Nguyen e McDaniel (2018) também aponta ler e destacar como principais técnicas empregadas pelos estudantes. A questão que resta, agora, é avaliar quais dessas práticas são efetivas e conduzem ao aprendizado, ou seja, potencializam a retenção e, eventualmente, a transferência para novos problemas. Esta é a discussão da próxima seção.

\section{TÉCNICAS DE APRENDIZADO EFICAZES}

Haveriam técnicas de estudo mais eficazes em potencializar o aprendizado? Seriam elas distintas das praticadas mais frequentemente pelos estudantes?

Das técnicas mais frequentemente reportadas na pesquisa da seção anterior, estudar na noite anterior ao dia da prova aparece em terceiro lugar. Para esta, o disposto na Seção 2 parece 
ser suficientemente esclarecedor. Se esta é a única forma de estudo empregada pelo estudante, o aprendizado irá se perder, a falta do sono impedirá a formação de estruturas cerebrais, a consolidação do aprendizado.

Quanto a ler e destacar - e cada vez mais assistir, o como importa mais que o quanto. Estas são as formas mais comuns e rápidas de continuar o pensamento ou compreensão do outro, mesclar com suas próprias experiências, capacitar-se para tirar proveito de oportunidades e para resolver novos problemas. Porém, a falta de reflexão é a grande armadilha destas técnicas (MIYATSU; NGUYEN; MCDANIEL, 2018). É preciso executá-las com o botão "pause" na ponta dos dedos: parar para refletir, associar, procurar o significado de palavras desconhecidas, elaborar perguntas enquanto lê, explicar o que acabou de estudar para si próprio (DUNLOSKY, 2013).

Comparadas a outras técnicas de estudo, no entanto, ler e destacar apresenta-se como uma técnica frequentemente inferior de aprendizado (ROEDIGER III; KARPICKE, 2006; KORNELL; BJORK, 2007; ADESOPE; TREVISAN; SUNDARARAJAN, 2017), principalmente por não ser executada de forma adequada. O estudo de Roediger III e Karpicke (2006), por exemplo, comparou o efeito no aprendizado entre ler repetidamente um texto $v s$ testar ou relembrar conceitos do texto lido sem o ler novamente. Lembre-se novamente da Seção 2, que destacou o poder da recuperação em fortalecer as sinapses e criar um caminho mais forte para relembrar da informação posteriormente. No experimento, 118 estudantes de graduação da Universidade de Washington fizeram a leitura de dois textos: um sobre o sol e outro sobre lontras marinhas, cada um com 30 ideias distintas, fatos sobre seus respectivos assuntos. Os estudantes deveriam escrever numa folha de papel, depois do estudo, tudo que se lembrassem do texto lido, sem se importar com ordem ou escrita correta. Na configuração do experimento, um grupo chamado LLLL apenas leu o texto em quatro blocos de estudo de cinco minutos (uma média de 14,2 leituras por estudante). Outro grupo, LLLT, leu o texto em três blocos e no último fez um teste prático (10,3 leituras do texto). O terceiro grupo, LTTT, leu o texto em média 3,4 vezes no primeiro bloco e nos três blocos seguintes realizou testes práticos. Alguns participantes fizeram um teste final cinco minutos depois e outros voltaram em uma semana para fazê-1o ${ }^{6}$.

A Figura 6a apresenta o resultado do experimento. No teste que ocorreu cinco minutos após o treinamento, quem leu mais se saiu melhor, ocorreu uma espécie de aprendizado ou lembrança de curto prazo. No entanto, a situação se inverte completamente depois de uma semana. O grupo que testou mais se saiu melhor. Quem somente leu lembrou-se de apenas $40 \%$ dos conceitos. Mais surpreendente foi o resultado do teste de confiança (Figura 6b): o grupo que mais leu, LLLL, foi também o mais confiante em se lembrar dos conceitos após uma semana. Perceba que os estudantes confiam mais na técnica que não dá resultado a longo prazo. Note, ainda, que este experimento comparou a leitura sem reflexão contra testar e relembrar. Apesar da data do estudo, sua clareza é apelativa. Um estudo mais recente foi feito por Brame e Biel (2015)

\footnotetext{
${ }^{6}$ Qual o seu nível de confiança, de 1 a 7 , em relembrar dentro de uma semana das 30 ideias de um texto? Qual seria o seu método preferido de estudo dentre os três apresentados?
} 
e uma meta análise com dezenas de repetições deste experimento pode ser vista em (ADESOPE; TREVISAN; SUNDARARAJAN, 2017).

Figura 6: Reler ou Relembrar? (a) Resultado em 5 min e 1 semana e (b) Resultado do teste de confiança.

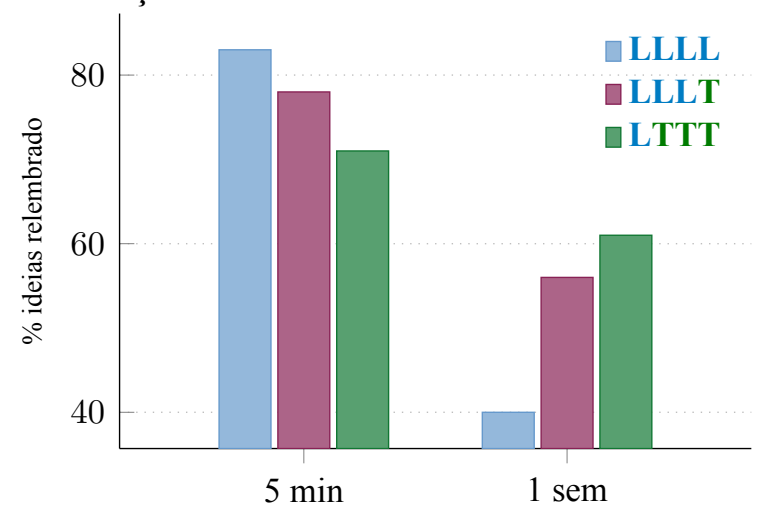

(a)

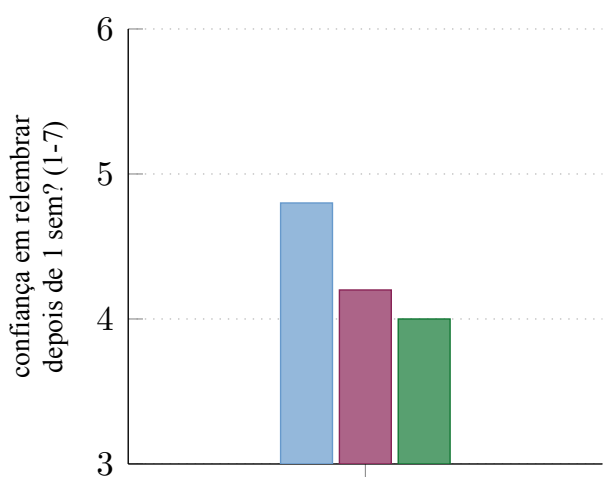

(b)

Fonte: O autor. Dados originais de (ROEDIGER III; KARPICKE, 2006).

Tão importante quanto relembrar é espaçar as repetições ou seções de reestudo. No entanto, por exigir uma maior disciplina do estudante, para organizar e seguir um calendário de estudo, raramente é uma técnica empregada, como foi reportado pelos próprios estudantes (Seção 4). Estudar de forma espaçada é estudar um determinado assunto ou conceito algumas vezes, espaçando as seções de estudo com tempo livre, ou com outras atribuições. Ao contrário, estudar de forma consecutiva é estudar um determinado assunto ou conceito três vezes repetidas e só depois parar para outros afazeres ou atribuições, ou até mesmo distração ${ }^{7}$. Estudar de forma consecutiva resulta em uma falsa percepção de aprendizado; o que se estuda é rapidamente esquecido. Quando o estudante passa a noite anterior à prova estudando, está fazendo-o de forma consecutiva. Alguns dias após fazer a prova não mais se lembrará do que estudou. Ao contrário, estudar de forma espaçada, principalmente usando a técnica de relembrar antes de reler, resultará em aprendizado duradouro. No entanto, o resultado não ocorre a curto prazo e o estudante terá a percepção de que estudar será mais difícil (CEPEDA et al., 2006; KORNELL; BJORK, 2008; DUNLOSKY, 2013; BJORK; DUNLOSKY; KORNELL, 2013; WAHLHEIM; DUNLOSKY; JACOBY, 2011; SAH, 2017).

É possível, ainda, estudar de forma intercalada ou agrupada. Este é um conceito muito importante no aprendizado de solução de problemas. Agrupado é quando estuda-se três vezes A seguido de tempo livre, depois passa-se para B, depois para $\mathrm{C}$. Intercalado é quando os conceitos são mesclados: numa primeira sessão estuda-se $\mathrm{A}$, depois $\mathrm{B}$, depois $\mathrm{C}$, seguido de tempo livre, na outra estuda-se B, A, C, e assim por diante ${ }^{8}$. Tradicionalmente, os livros agrupam os conteúdos de forma que o estudo de um conceito é seguido pela prática exaustiva

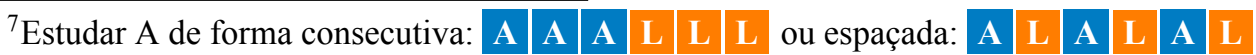

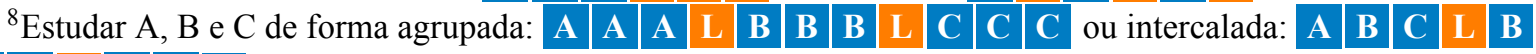
\begin{tabular}{l|l|l|l|l|l|}
$\mathbf{C}$ & $\mathbf{A}$ & $\mathbf{L}$ & $\mathbf{C}$ & $\mathbf{A}$ & $\mathbf{B}$ \\
\hline
\end{tabular}
} 
de exercícios antes de se passar para um novo conceito. Não se move para o próximo conceito antes de dominar completamente o anterior. Alguns livros de matemática, tanto no ensino básico quanto superior, por exemplo, até hoje são organizados desta forma e não disponibilizam listas intercaladas de exercícios ${ }^{9}$. Estudar de forma agrupada faz com que o estudante não treine a identificação da técnica adequada para solução do problema, pois ao ficar de frente para o exercício já sabe que trata-se da técnica que acabara de ler a respeito. Na vida, os problemas não aparecem com etiquetas que dizem qual conceito pode ser usado para resolvê-los. É preciso treinar os estudantes a identificar, desde cedo, a utilidade do que aprendem e a percepção do como podem usar o que sabem na solução de desafios (ROHRER; TAYLOR, 2007; KORNELL; BJORK, 2008; VLACH; ANKOWSKI; SANDHOFER, 2012; BIRNBAUM et al., 2013; YAN, 2014).

Este conjunto de técnicas de estudo, juntamente com outras técnicas voltadas à geração ou criação de artefatos, como produção de mnemônicos, invenção de jogos para estudar, uso de flashcards, é por vezes chamado de "dificuldades desejadas". Dificuldades porque o estudante terá que ser muito mais atento durante o estudo e eventualmente perceberá que sua velocidade de aprendizado irá diminuir, se comparado com o mero desempenho nas provas depois de estudar durante a noite. No entanto, elas frequentemente melhoram a retenção de longo prazo e transferência para novos problemas, e por isso são desejadas (BJORK, 1994; BJORK; DUNLOSKY; KORNELL, 2013).

Os estudantes, no entanto, não possuem uma boa percepção a respeito da efetividade destas técnicas (CARPENTER; ENDRES; HUI, 2020). Na maioria dos experimentos e referências aqui citados, o teste de meta cognição aparece invertido com o resultado verificado, ou seja, os estudantes acreditam aprender de formas que de fato não conduzem a um aprendizado duradouro, como foi o caso do experimento entre ler e relembrar, por exemplo. Levar este esclarecimento para a sala de aula é, portanto, de fundamental importância na conscientização de nossos estudantes. Ressalta-se, porém, que muita pesquisa ainda é necessária para confirmar a aplicabilidade mais ampla destes resultados nas variadas disciplinas e metodologias de ensino existentes.

\section{CRIATIVIDADE}

Não há dúvida que ser criativo é uma habilidade essencial do ambiente de trabalho do século 21 (NAKANO; WECHSLER, 2018). Muitas são também as tarefas de um estudante que requerem algum exercício de criatividade: escrever redações, dissertações, teses; resolver problemas ou situações-problema, criar algoritmos, dentre outras. Existem várias definições para

\footnotetext{
${ }^{9}$ Uma pesquisa recente constatou que, no ensino de matemática nos anos iniciais, os livros didáticos não compreendem nem observam a metodologia de resolução de problemas estabelecida pelo MEC/PCN (CARDOSO; OLIVEIRA, 2021). Longe, portanto, parece estarmos de apresentar estes exercícios de forma espaçada ou intercalada, que é o que discutimos aqui como técnica eficaz de aprendizado.
} 
criatividade mas não há nenhuma universalmente aceita (TREFFINGER; YOUNG et al., 2002). Algumas definições relevantes para criatividade são:

Criatividade é como um tipo de pensamento novo, ou nova forma de pensar, na qual as pessoas redefinem problemas, percebem lacunas de conhecimento, geram e analisam ideias, e aceitam maiores riscos no desenvolvimento das mesmas (DALY; MOSYJOWSKI; SEIFERT, 2014, p. 418, tradução do autor) ${ }^{10}$.

Criatividade é a produção de ideias novas e úteis em qualquer domínio (AMABILE et al., 1996, p. 1155, tradução do autor).

Pensamento criativo é a habilidade de combinar e conectar ideias de novas formas, entre conceitos, campos distintos do conhecimento, projetos, ideias ou experiências. (FINKE; WARD; SMITH, 1996) apud (DALY; MOSYJOWSKI; SEIFERT, 2014, p. 418, tradução do autor).

Percebe-se que há uma tendência a convergir em torno da combinação de ideias existentes em novas ideias úteis. Estas definições, observadas objetivamente, podem indicar que uma direção possível para o aprendizado da criatividade seja a ampliação do arsenal de conceitos, técnicas e habilidades de um indivíduo. Sendo criatividade a habilidade de combinar e conectar, é necessário que se tenha o quê combinar, conectar. Também objetivamente, aparenta uma conexão com o discutido na Seção 2: ao aprender novos assuntos, técnicas, conceitos, criase oportunidades de associação, de combinação de ideias existentes.

No entanto, nota-se com apenas esta análise objetiva, a falta do 'como' combinar e conectar. Portanto, longe de ser o único aspecto observado a respeito de criatividade, a pesquisa em criatividade estende-se pela questão dos sonhos, intuição, incubação de ideias, além de outras formas de pensamento tidas como não estruturadas, que podem produzir novidades: novas organizações, classificações, conceitos e ideias (STEVEN M. SMITH; FINKE, 1995; SMITH, 1995). Trata-se de uma construção multidimensional, envolvendo variáveis cognitivas, características pessoais, família, aspectos educacionais, e também elementos sociais e culturais (NAKANO; WECHSLER, 2018).

No sentido de ampliação do domínio de conceitos, técnicas e habilidades, não é raro ouvirmos dos estudantes: "não sei porque estudo isto, nunca irei utilizar!”. Por um lado, o aprendiz, ao reforçar este comportamento, perde um importante objetivo do ensino, que é o de formar um conjunto de conhecimentos que pode ser transferido, aplicado, a problemas ainda não descobertos. Por outro, num mundo globalizado e conectado, cada vez menos as soluções para os problemas da humanidade vem de apenas um campo do conhecimento. É importante expandir os horizontes dos saberes, integrá-lo e interrelacioná-lo. Veja por exemplo a pesquisa de 2019 que conseguiu registrar a primeira foto de um buraco negro (AKIYAMA et al., 2019),

\footnotetext{
${ }^{10}$ Uma lista mais completa de referências para esta definição é apresentada por Daly, Mosyjowski e Seifert (2014).
} 
ou de sua 'sombra'. A lista de autores do artigo, publicado no The Astrophysical Journal Letters, possui 195 autores, das mais diversas áreas, de 143 instituições distintas!

Por último, mas também importante, criatividade não é uma habilidade de nascença, que alguns possuem e outros não (KIRTON, 2011; TREFFINGER; ISAKSEN; STEADDORVAL, 2005). Também não é só para artistas, músicos, poetas, e outros similares, pois está relacionada de forma mais ampla à solução de problemas novos, complexos, ambíguos e também à produção de ideias para transformar o nosso arredor (TREFFINGER; ISAKSEN; STEADDORVAL, 2005). Ainda, é algo que pode-se ensinar, aprender, afinal, existem métodos e técnicas cientificamente comprovados para aumentar a produtividade de ideias criativas (TREFFINGER; ISAKSEN; STEAD-DORVAL, 2005).

Dos vários fatores potenciais que podem interferir na criatividade, incluindo habilidades sociais e mudanças no ambiente, o que tem se mostrado mais efetivo em produzir ideias criativas é o treinamento dos estudantes em habilidades cognitivas (DALY; MOSYJOWSKI; SEIFERT, 2014). Entre tais habilidades cognitivas estão padrões de pensamento, traços e mecanismos que guiam e dirigem tarefas criativas (FINKE; WARD; SMITH, 1996).

Por se tratar de um processo cognitivo complexo, não conhecido em sua totalidade apesar da quantidade de estudos dedicados ao assunto (VAN HEERDEN, 2018), a quantidade de habilidades relacionadas ao 'ser criativo' é muito extensa. A lista categorizada de habilidades que se segue pode ser útil para guiar a aquisição das mesmas, o treinamento ou ensino, ou até o processo criativo de uma tarefa ou projeto. Importante notar que nenhuma pessoa possui todas essas habilidades ou as manifesta simultaneamente ou a todo tempo (TREFFINGER; YOUNG et al., 2002):

- Geração de ideias (pensamento divergente ou pensamento criativo): inclui características e habilidades relacionadas à fluência - conhecimento do assunto, flexibilidade, originalidade, elaboração e pensamento metafórico - através de metáforas;

- Desenvolvendo as ideias (pensamento convergente ou pensamento crítico): engloba características e habilidades em análise, sintetização, reorganização e redefinição, avaliação, encontrar relacionamentos, desejo de solucionar ambiguidades ou 'trazer ordem ao caos, desordem', e preferir a complexidade ou entendê-la;

- Abertura e coragem para explorar ideias (reflete traços relacionados aos interesses pessoais, experiências, atitudes e autoconfiança): sensibilidade ao problema, sensibilidade estética, curiosidade, senso de humor, habilidade de brincar, fantasiar e imaginar, assumir riscos, tolerância à ambiguidade, tenacidade - ser determinado, abertura à experimentação, sensibilidade emocional, adaptabilidade, intuição, vontade de crescer, relutância em aceitar asserções impostas antes do exame crítico, e integração de dicotomias ou conceitos opostos; e 
- Reflexão ou metacognição-ouvir a voz interior (entendimento do próprio ser sobre quem ele é, visão de onde quer chegar, e comprometimento para assumir o necessário para alcançar a visão): percepção da habilidade de criar, persistência ou perseverança, auto direcionamento, locus interno de controle - sentir-se responsável pelas próprias ações ao invés de responsabilizar os outros pelos acontecimentos, introspecção, liberdade de estereótipos, concentração, energia e ética de trabalho.

\section{CONSIDERAÇÕES FINAIS}

Neste estudo, apresentou-se aspectos do funcionamento da memória humana, ilusões frequentes em relação ao aprendizado e também técnicas mais efetivas, como o conceito de dificuldades desejadas, estudo espaçado, intercalação, testes distribuídos, aptidão e desenvolvimento da criatividade, com o objetivo de conscientizar os estudantes dos resultados da ciência e fomentar o aprendizado de longo prazo. Tal levantamento foi realizado consultandose a bibliografia em neurociência, educação, ensino, e psicologia cognitiva da memória e do aprendizado, bem como seus relevantes estudos, resultados, e revisões sistemáticas nas duas últimas décadas.

Longe do escopo estava contemplar o todo do aprendizado e discutir, principalmente, os inter-relacionamentos com os estudos específicos de cada área do conhecimento. Afinal, cada área da ciência possui sua própria literatura fundamental em como ensinar os mais diversos assuntos, conceitos e ferramentas. Um estudo neste sentido exige um esforço amplo e conjunto das várias áreas da ciência e, naturalmente, um esforço interdisciplinar dos pesquisadores. É um trabalho futuro importante.

Acredita-se ser, este levantamento, um passo importante para fomentar o aprendizado eficaz. As técnicas apresentadas são gerais e não restritas ao local de estudo ou metodologia de ensino aprendizagem. Porém, acreditamos serem imprescindíveis neste momento em que ocorre a expansão das iniciativas de ensino $\mathrm{EaD}$ e remoto, principalmente as implantadas recentemente nas Escolas, Colégios e Universidades brasileiras devido à crise de Covid-19.

\section{REFERÊNCIAS}

ADESOPE, Olusola O; TREVISAN, Dominic A; SUNDARARAJAN, Narayankripa. Rethinking the use of tests: A meta-analysis of practice testing. Review of Educational Research, Sage Publications Sage CA: Los Angeles, CA, v. 87, n. 3, p. 659-701, 2017. Citado nas pp. 11, 12.

AKIYAMA, Kazunori et al. First M87 Event Horizon Telescope Results. I.The Shadow of the Supermassive Black Hole. The Astrophysical Journal Letters, v. 875, n. L1, p. 17, 2019. DOI: 10.3847/2041-8213/ab0ec7. Citado na p. 14. 
AMABILE, Teresa $\mathrm{M}$ et al. Assessing the work environment for creativity. Academy of management journal, Academy of Management Briarcliff Manor, NY 10510, v. 39, n. 5, p. 1154-1184, 1996. Citado na p. 14.

AZEVEDO, Frederico A.C. et al. Equal numbers of neuronal and nonneuronal cells make the human brain an isometrically scaled-up primate brain. The Journal of Comparative Neurology, Wiley, v. 513, n. 5, p. 532-541, 2009. DOI: 10.1002/cne.21974. Citado na p. 4.

BACICH, Lilian; MORAN, José (org). Metodologias ativas para uma educação inovadora: uma abordagem téorico-prática. Porto Alegre, SC: Penso, 2018. Disponível em: $<$ https://bit.1y/3vcwGKt>. Acesso em: 11 mar. 2021. Citado na p. 2.

BARTOL THOMAS M, Jr et al. Nanoconnectomic upper bound on the variability of synaptic plasticity. eLife, eLife Sciences Publications, Ltd, v. 4, 2015. DOI: 10.7554/elife.10778. Citado nas pp. 5, 7.

BIRNBAUM, Monica $S$ et al. Why interleaving enhances inductive learning: The roles of discrimination and retrieval. Memory \& cognition, Springer, v. 41, n. 3, p. 392-402, 2013. Citado na p. 13.

BJORK, Robert A. Memory and metamemory considerations in the instruction of human beings. Metacognition: Knowing about knowing, v. 185, 1994. Citado na p. 13.

BJORK, Robert A.; DUNLOSKY, John; KORNELL, Nate. Self-Regulated Learning: Beliefs, Techniques, and Illusions. Annual Review of Psychology, Annual Reviews, v. 64, n. 1, p. 417-444, 2013. DOI: 10.1146/annurev-psych-113011-143823. Citado nas pp. 2, 3, 12, 13.

BRAME, Cynthia J; BIEL, Rachel. Test-enhanced learning: the potential for testing to promote greater learning in undergraduate science courses. CBE-Life Sciences Education, Am Soc Cell Biol, v. 14, n. 2, es4, 2015. DOI: 10.1187/cbe.14-11-0208. Citado na p. 11.

BRASIL. Lei $N^{\circ}$ 5.692, Fixa Diretrizes e Bases para o ensino de $1^{\circ}$ e $2^{\circ}$ graus, e dá outras providências., 1971. Disponível em: <www.planalto.gov.br/ccivil_03/leis/15692.htm>. Acesso em: 11 mar. 2021. Citado na p. 2.

CARDOSO, Márcia Regina Gonçalves; OLIVEIRA, Guilherme Saramago de. A resolução de problemas como metodologia para o ensino de matemática nos anos iniciais. Itinerarius Reflectionis, v. 17, n. 2, p. 1-21, 2021. DOI: 10.5216/rir.v17i2.62867. Citado na p. 13.

CARPENTER, Shana K; ENDRES, Tino; HUI, Luotong. Students' use of retrieval in self-regulated learning: Implications for monitoring and regulating effortful learning experiences. Educational Psychology Review, Springer, p. 1-26, 2020. Citado na p. 13.

CEPEDA, Nicholas J. et al. Distributed practice in verbal recall tasks: A review and quantitative synthesis. Psychological bulletin, American Psychological Association, v. 132, n. 3, p. 354, 2006. Citado na p. 12.

COÊLHO, Ildeu Moreira (org.) Escritos sobre o sentido escola. Campinas, SP: Mercado de Letras, 2012. p. 408. ISBN 978-85-7591-255-3. Citado na p. 2.

CURCIO, Giuseppe; FERRARA, Michele; DE GENNARO, Luigi. Sleep loss, learning capacity and academic performance. Sleep medicine reviews, Elsevier, v. 10, n. 5, p. 323-337, 2006. Citado na p. 8.

DALY, Shanna R.; MOSYJOWSKI, Erika A.; SEIFERT, Colleen M. Teaching creativity in engineering courses. Journal of Engineering Education, Wiley Online Library, v. 103, n. 3, p. 417-449, 2014. Citado nas pp. 14, 15.

DUNLOSKY, John. Strengthening the student toolbox: Study strategies to boost Learning. American Educator, ERIC, v. 37, n. 3, p. 12-21, 2013. Citado nas pp. 3, 11, 12.

FINKE, Ronald A; WARD, Thomas B; SMITH, Steven M. Creative cognition: Theory, research, and applications. Bradford Book, p. 256, 1996. Citado nas pp. 14, 15. 
HARTWIG, Marissa K; DUNLOSKY, John. Study strategies of college students: Are self-testing and scheduling related to achievement? Psychonomic bulletin \& review, Springer, v. 19, n. 1, p. 126-134, 2012. Citado na p. 10.

JAMIESON, Daniel et al. Investigating the links between adolescent sleep deprivation, fronto-limbic connectivity and the onset of mental disorders: a review of the literature. Sleep medicine, Elsevier, v. 66, p. 61-67, 2020. Citado na p. 8.

JOHNSON, Roger T; JOHNSON, David W. Active learning: Cooperation in the classroom. The annual report of educational psychology in Japan, The Japanese Association of Educational Psychology, v. 47, p. 29-30, 2008. Citado na p. 2.

KIRTON, M. J. Adaption-Innovation: In the Context of Diversity and Change. New York, NY: Routledge, 2011. p. 408. Citado na p. 15.

KLINZING, Jens G.; NIETHARD, Niels; BORN, Jan. Mechanisms of systems memory consolidation during sleep. Nature Neuroscience, Springer Science e Business Media LLC, v. 22, n. 10, p. 1598-1610, 2019. DOI: 10.1038/s41593-019-0467-3. Citado na p. 8.

KORNELL, Nate; BJORK, Robert A. The promise and perils of self-regulated study. Psychonomic bulletin \& review, Springer, v. 14, n. 2, p. 219-224, 2007. Citado nas pp. 9-11.

Learning concepts and categories: Is spacing the 'enemy of induction'? Psychological science, SAGE Publications Sage CA: Los Angeles, CA, v. 19, n. 6, p. 585-592, 2008. Citado nas pp. $12,13$.

LITWIN-KUMAR, Ashok et al. Optimal Degrees of Synaptic Connectivity. Neuron, Elsevier, v. 93, n. 5, p. 1153-1164, 2017. DOI: 10.1016/j .neuron. 2017.01.030. Citado nas pp. 5, 7.

LIU, Haiqiong; CHEN, Aihua. Roles of sleep deprivation in cardiovascular dysfunctions. Life Sciences, v. 219, p. 231-237, 2019. DOI: 10.1016/j.lfs.2019.01.006. Citado na p. 8.

MEC; CONSED; UNDIME. Base Nacional Comum Curricular: Educação é a Base. Brasília: Ministério da Educação, 2017. Disponível em: <https://bit.ly/bnccbook>. Acesso em: 11 mar. 2021. Citado na p. 2.

MIYATSU, Toshiya; NGUYEN, Khuyen; MCDANIEL, Mark A. Five popular study strategies: Their pitfalls and optimal implementations. Perspectives on Psychological Science, Sage Publications Sage CA: Los Angeles, CA, v. 13, n. 3, p. 390-407, 2018. Citado nas pp. 10, 11.

NAKANO, Tatiana de Cassia; WECHSLER, Solange Muglia. Creativity and innovation: Skills for the 21 st Century. Estudos de Psicologia (Campinas), FapUNIFESP (SciELO), v. 35, n. 3, p. 237-246, 2018. DOI: 10.1590/1982-02752018000300002. Citado nas pp. 13, 14.

OLIVEIRA, José Silvio de; OLIVEIRA, Thiago Borges de (org). Vozes nas instituições de ensino públicas e privadas no contexto da covid-19. Jataí, GO: Editora da UFJ, 2020. Disponível em: <https://bit.ly/editoraufj>. Acesso em: 11 mar. 2021. Citado na p. 3.

OPENSTAX. Parts of a Neuron. In: OPENSTAX Anatomy and Physiology. [S.1.: s.n.], 2021. CC BY 4.0. Disponível em: <https://bit.1y/20020yD>. Acesso em: 12 mar. 2021. Citado na p. 4.

PEIGNEUX, Philippe et al. Sleeping brain, learning brain. The role of sleep for memory systems. Neuroreport, LWW, v. 12, n. 18, a111-a124, 2001. Citado na p. 8.

ROEDIGER III, Henry L; KARPICKE, Jeffrey D. The power of testing memory: Basic research and implications for educational practice. Perspectives on psychological science, SAGE Publications Sage CA: Los Angeles, CA, v. 1, n. 3, p. 181-210, 2006. Citado nas pp. 11, 12.

ROHRER, Doug; TAYLOR, Kelli. The shuffling of mathematics problems improves learning. Instructional Science, Springer, v. 35, n. 6, p. 481-498, 2007. Citado na p. 13. 
SAH, Pankaj. Memories are Made of This. The Brain: Learning \& Memory, The Queensland Brain Institute, v. 2, 2017. Disponível em: <https://qbi .uq.edu .au/learning>. Acesso em: 1 set. 2020. Citado nas pp. 6-8, 12.

SMITH, Steven M. The creative cognition approach. In: Cambridge, MA: The MIT Press, 1995. Fixation, incubation, and insight in memory, problem solving, and creativity, p. 135-155. Citado na p. 14.

STEVEN M. SMITH, T.B. Ward; FINKE, R.A. The creative cognition approach. Cambridge, MA: The MIT Press, 1995. p. 359. Citado na p. 14.

TOUR GROUP/RICE UNIVERSITY. A scanning electron microscope image shows details of a 1-kilobit crossbar memory array designed and built at Rice University using silicon oxide as the active element. Houston, TX: [s.n.]. Disponível em: $<$ https : //bit.ly/3t9Canx $>$. Acesso em: 12 mar. 2021. Citado na p. 7.

TREFFINGER, Donald J; ISAKSEN, Scott G; STEAD-DORVAL, K Brian. Creative problem solving: An introduction. Waco, TX: Prufrock Press Inc., 2005. p. 4-5. Citado na p. 15.

TREFFINGER, Donald J; YOUNG, Grover C et al. Assessing Creativity: A Guide for Educators.

National Research Center on the Gifted and Talented, ERIC, 2002. Disponível em:

$<$ https://files.eric.ed.gov/fulltext/ED505548.pdf >. Acessado em setembro de 2020.

Citado nas pp. 14, 15.

VAN HEERDEN, Ariana. Neuroimaging as contributor to understanding creativity. South African Journal of Art History, AHWG, v. 33, n. 3, p. 1-12, 2018. Citado na p. 15.

VLACH, Haley A; ANKOWSKI, Amber A; SANDHOFER, Catherine M. At the same time or apart in time? The role of presentation timing and retrieval dynamics in generalization. Journal of

Experimental Psychology: Learning, Memory, and Cognition, American Psychological Association, v. 38, n. 1, p. 246, 2012. Citado na p. 13.

WAHLHEIM, Christopher N; DUNLOSKY, John; JACOBY, Larry L. Spacing enhances the learning of natural concepts: An investigation of mechanisms, metacognition, and aging. Memory \& cognition, Springer, v. 39, n. 5, p. 750-763, 2011. Citado na p. 12.

YAN, Veronica. Learning Concepts and Categories from Examples: How Learners' Beliefs Match and Mismatch the Empirical Evidence. 2014. Tese (Doutorado). Disponível em: <https://escholarship.org/uc/item/91q7z7z4>. Acesso em: 12 mar. 2021. Citado na p. 13.

YAN, Veronica X; CLARK, Courtney M; BJORK, Robert A. From the laboratory to the classroom: Translating science of learning for teachers. In: New York, NY: Routledge, 2017. Memory and metamemory considerations in the instruction of human beings revisited, p. 61-78. Citado na p. 7.

YANG, G. et al. Sleep promotes branch-specific formation of dendritic spines after learning. Science, American Association for the Advancement of Science (AAAS), v. 344, n. 6188, p. 1173-1178, 2014. DOI: $10.1126 /$ science.1249098. Citado nas pp. 5, 8, 9 . 